\section{DO IMPERFEITO AO MAIS-QUE-PERFEITO: A KALOKAGATHÍA DOS ATLETAS PARALÍMPICOS}

\author{
FROM IMPERFECT TO HIGHLY PERFECT: THE KALOKAGATHÍA OF \\ PARALYMPIC ATHLETES
}

DE LO IMPERFECTO A LO MÁS QUE PERFECTO: LA KALOKAGATHÍA DE LOS ATLETAS PARALIMMPICOS

\author{
Luciane Maria Micheletti Tonon* , Katia Rubio*
}

Keywords:

Athletes.

Philosophy.

Athletic Injuries.
Disabled Persons.

\begin{abstract}
This article aims to discuss kalokagathia (the good and the beautiful) in the passage of the athlete who transcended physical limitations or imperfections imposed by disability to the position of excellence achieved in a career as Paralympic athlete. When it comes to sports, the "imperfect" metaphor points out who people with disabilities are and where they are, when and why sports practices become accessible, and where they are today. Biographical narratives were used as a method, which allowed understanding the transition processes of the athletes studied. All of them were on an Olympic career path when they suffered an accident or illness that physically limited them. What has been seen and heard of these athletes is their love of life shining over any atrophied muscles, darkness in their visual fields or missing body parts.
\end{abstract}

Palabras clave: Personas con discapacidad. Atletas. Traumatismo en Atletas. Filosofía.
Resumen: El presente artículo tiene como objetivo discutir la kalokagathía (lo bueno y lo bello) del atleta que trascendió las limitaciones físicas, o imperfecciones, impuestas por la deficiencia hacia la posición de excelencia alcanzada en la carrera de atleta paralímpico. En lo que se refiere al deporte, cabe la metáfora "imperfecto" para situar quiénes son y dónde están las personas con discapacidad, cuándo y por qué las prácticas deportivas se vuelven accesibles y dónde se encuentran en la actualidad. Para ello, como método se utilizan las narrativas biográficas, que permitieron entender los procesos de transición de los atletas estudiados. Todos ellos estaban en trayectoria de carrera olímpica cuando sufrieron un accidente o enfermedad que los limitó físicamente. Lo que se vio y se oyó de esos atletas es el amor a la vida reluciendo por encima de cualquier musculatura atrofiada, de cualquier penumbra en el campo visual o de cualquier parte del cuerpo que falte.
*Universidade de São Paulo. São Paulo, SP, Brasil.

E-mail: luciane.tonon@usp.br; katrubio@usp.br

Recebido em: 02-04-2018 Aprovado em: 28-09-2018

DOI: https://doi.org/10.22456/1982-8918.81675 (c) (1) (8) Licence 


\section{INTRODUÇÃO}

Na gramática da língua portuguesa, o pretérito "imperfeito" do indicativo diz respeito a um passado que não foi completamente terminado; e o pretérito "mais-que-perfeito", majoritariamente, é utilizado em exclamações, em linguagem poética ou na sua forma composta. Tais conceitos, simbolicamente, não estão longe do objeto de estudo aqui abordado, que é ressaltar a kalokagathía - conceito grego que traduz "o bom e o belo", na passagem do indivíduo que transcende de um corpo com limitações físicas, ou ainda daquele que não fora completamente terminado, o "imperfeito", para uma posição de excelência alcançada pelo atleta paralímpico em suas performances e resultados; o "mais-que-perfeito", ou seja, o que merece exclamações. Os termos "imperfeito" ou "mais-que-perfeito" são empregados aqui como metáforas, na tentativa de expressar os superlativos de uma impossibilidade autoimposta ou determinada socialmente. $O$ que se faz neste estudo é o enlace da pesquisa com a poiéses. Prática essa defendida pelo filósofo Gaston Bachelard (2002a; 2010b; 2016c), que alia a arte à ciência como promotora de empatia, compreensão, entendimento e comoção sobretudo, de grande valia para a pesquisa. Depois de dedicar uma vida toda como cientista evolucionista, Bachelard se rende à poesia dizendo: "O poeta não me confere o passado de sua imagem, e, no entanto, ele se enraíza imediatamente em mim" (BACHELARD, 2002 p. 2).

Ao se falar em passagem, o texto se fundamenta na leitura de Van Gennep (2012), que considera a vida individual regida por ritos e rituais de passagem sucessivos como uma idade à outra e de uma ocupação à outra. Nesse contexto, serão destacados na história e pela história alguns rituais de passagem, de uma condição física à outra; de atletas de alto rendimento que estavam na trajetória de carreira para se tornarem atletas olímpicos e por alguma eventualidade, acidente ou doença, se recriaram no esporte paralímpico. "O rito sugere e insinua a esperança de todos os homens na sua inesgotável vontade de passar e ficar, de esconder e mostrar, de controlar e libertar, nessa constante transformação do mundo e de si mesmo que está inscrita no verbo viver em sociedade" (Da MATTA in prefácio GENNEP, 2012, p.2). Por este mesmo caminho, Farias (2018) define rito ou ritual como narrativa memorial de uma experiência formalizada, constituída pela repetição de uma série expressiva de atos, objetos, textos, contextos, cronologia e espaços específicos marcados por uma intenção retórica e por uma dimensão simbólica, cujo sentido e a função são partilhados por um determinado grupo. "[...] são processos narrativos de evocação e rememoração de histórias de origem - mitos - ou de importância destacável naquilo que foi experimentado e que se quer experimentar novamente, no âmbito do sagrado ou do profano" (FARIAS, 2018 p. 104).

No caso deste estudo, as dimensões simbólicas poderão ser vistas na primeira parte do texto, intitulada "Do imperfeito...", que situa as pessoas com deficiência na história desde a antiguidade, quando as práticas esportivas foram criadas, ressaltando como eram os rituais, o convívio e tratamento dessas pessoas. A evolução da história vem com o subtítulo "[...] ao mais-que-perfeito", simbolizando não só um avanço na linha do tempo como na mudança dos conceitos do bom e do belo; além de todo o desenvolvimento dos Jogos Paralímpicos, que apresentam a kalokagathía dos atletas da atualidade. "Sendo o evento esportivo que mais atrai a atenção da sociedade para as pessoas com deficiência, os Jogos Paralímpicos têm papel fundamental sobre o modo como essas pessoas são reconhecidas" (HARDIN; HARDIN, 2004, p. 10). 
Os rituais de passagem sugeridos por Van Gennep (2012), entre eles os ritos de separação, ritos de margem e ritos de agregação, que permitem entender o funcionamento das passagens naturais da existência do homem, serão percebidos na fala dos atletas colaboradores, ao narrarem suas experiências, pela percepção que tiveram do antes e do depois de vivenciarem suas devidas mudanças físicas e consequentemente suas posições na trajetória paralímpica, validando assim o objetivo proposto.

\section{OBJETIVO E MÉTODO}

O objetivo deste artigo é discutir a kalokagathía (o bom e o belo) na passagem do atleta que transcendeu as limitações físicas, ou imperfeições, impostas pela deficiência para a posição de excelência alcançada na carreira de atleta paralímpico. Para tanto, serão utilizadas as histórias de vida dos atletas: Gustavo Henrique Araújo, velocista de baixa-visão; a nadadora Susana Schnarndorf, acometida por doença degenerativa, que limita seus movimentos; e o cavaleiro Rodolpho Riskala, que sofreu amputações em função de uma meningite. Todos eles eram atletas de nível olímpico antes de serem levados à condição de paralímpicos. Tais histórias foram colhidas através do método de narrativas biográficas (RUBIO, 2016), concebido a partir da fala do sujeito, respeitando o lugar da fala e a representatividade do que ele traz na memória, sem intervenções do pesquisador. Vale ressaltar também a importância da seleção subjetiva daquilo que é recordado pelo narrador e que tem como referência o ambiente vivido. Benjamin (1987) ressalta que metade da arte narrativa está em evitar explicações, por isso 0 respeito ao conteúdo bruto das falas.

O presente projeto faz parte da pesquisa "Memórias Olímpicas por Atletas Olímpicos Brasileiros", aprovada pelo Comitê de Ética da Escola de Educação Física da Universidade de São Paulo no processo 0052.0.342.000-09. Os atletas foram entrevistados e assinaram o Termo de Consentimento Livre e Esclarecido, autorizando o uso dos dados na pesquisa científica. As entrevistas foram realizadas pelos membros do Grupo de Estudos Olímpicos (GEO) da Universidade de São Paulo, gravadas em vídeo e posteriormente transcritas. Todos os encontros foram presenciais, sem questionamento diretivo, mas num processo dialógico entre pesquisador e colaborador a partir do estímulo: "conte-me sua história de vida".

\subsection{Do imperfeito...}

A expressão grega Kalokagathía é derivada de dois adjetivos: kalós = lindo, bonito (exteriormente), decente, honesto, nobre (interiormente) + agathós = honesto, bom, nobre, corajoso, digno de admiração. $O$ termo reflete ideais de harmonia e unidade altamente valorizados na Antiguidade - particularmente na Grécia helênica. A própria palavra em grego pode ser traduzida como "valor moral", "honestidade", "virtude" (LIDDEL; SCOTT, 1968). Consequentemente, kalokagathía como "o belo e o bom" era um ideal para ser alcançado através da educação e do estilo de vida dos gregos, (DÜRRIGL, 2002), e remete ao pensamento platônico sobre o que é bom (como uma reflexão de o "bom ideal") só pode ser bonito e viceversa.

Platão escreveu em Lysis: 'Porque eu afirmo que o bom é o belo'. Ele uniu aparência externa com uma qualidade interna. De forma simplificada, pode-se dizer que apenas aquele que possui ambas as qualidades (quem é bonito, justo, mas também honesto e vertical) pode ser considerado belo (DÜRRIGL, 2002, p. 208). 
Com esses atributos, os homens gregos eram então preparados para a guerra, para defender a polis (cidade) e se tornariam heróis. É nesse cenário que surgem as práticas atléticas, que, segundo Rubio (2001), acompanham a história grega como um elemento intrínseco à condição humana, seja na formação de sua constituição física, seja na atividade competitiva. "Parte da formação do cidadão residia no processo de purificação do espírito, vigente na ideia de que não era possível a perfeição sem a beleza do corpo" (RUBIO, 2001, p. 112).

Nessa perspectiva, o feio e malformado (falta de proporção) não usufruía da mesma representação heroica. Exemplo dessa condição pode ser encontrado no mito de Tersites. $\mathrm{Na}$ Guerra de Troia participaram muitos heróis, descritos como valentes, fortes e corajosos. Tersites, porém, foi um exemplo do anti-herói. Manco, estrábico, tinha peito afundado, cabeça pontuda e cabelos ralos. "[...] o mais feio dos homens que haviam chegado à frente de ílion: vesgo, manco de uma perna, o peito cavado entre os ombros curvados para frente, sobre a cabeça pontuda, vegetava-lhe rala penugem" (HOMERO, $1961{ }^{1}$ apud GOMES, 2014, p.34).

A discriminação e o preconceito com relação às pessoas com deficiência ocorreram em diferentes regiões ao longo da história. Amaral (1994) afirma que as anomalias e deficiências sempre existiram na história da humanidade: ou como um sinal da presença dos deuses ou dos demônios; ou algo da esfera do supra-humano ou do âmbito do infra-humano. "Do venerável saber do oráculo cego à 'animalidade' da pessoa a ser extirpada do corpo sadio da humanidade. Assim foi por muito tempo, em várias civilizações ancestrais da nossa" (AMARAL,1994, p. 14).

De acordo com Silva (1987), em Esparta, alguns rituais de separação das crianças com deformidades eram legitimados. Todo pai de recém-nascido das famílias conhecidas como homoio (ou seja, "os iguais") deveria apresentar seu filho a um Conselho de espartanos, independentemente se tivesse alguma deficiência ou não. Se esta comissão de sábios avaliasse que o bebê era normal e forte, ele era devolvido ao pai, que tinha a obrigação de cuidá-lo até os sete anos. No entanto, se a criança parecesse "feia, disforme e franzina", indicando algum tipo de limitação física, cabia aos anciãos ficar com a criança e, em nome do Estado, levá-la para o Apothetai (que significa "depósitos"), um abismo de onde a criança era jogada, dando fim à sua vida, "[...] pois tinham a opinião de que não era bom nem para a criança nem para a república que ela vivesse, visto que, desde o nascimento, não se mostrava bem constituída para ser forte, sã e rija durante toda a vida" (LICURGO DE PLUTARCO apud SILVA, 1987, p. 105).

Nas narrativas religiosas como Bíblia, o Torá, ou o Alcorão é comum encontrar registros da deformidade. Nas tábuas da Lei, Moisés registra que pessoas com deformidades não poderiam chegar até o altar para ofertar sacrifícios ao Senhor, para que não profanassem os santuários de Deus.

Pois nenhum homem em que houver alguma deformidade se chegará; como homem cego, ou coxo, ou de nariz chato, ou de membros demasiadamente compridos, ou homem que tiver quebrado o pé, ou a mão quebrada, ou corcunda, ou anão, ou que tiver defeito no olho, ou sarna, ou impinge, ou quem tiver testículo mutilado (LEVÍTICO 21:18, online).

Já na era depois de Cristo (d.C.), as citações religiosas certificam uma conduta de inclusão dos fisicamente limitados. Para essa escritura, tal condição era sinônima de carregar, o pecado: "E Jesus, vendo a fé deles, disse ao paralítico: Filho! perdoados estão os teus pecados" (MARCOS 2:5, online). Os coxos e aleijados não eram mais exterminados, mas viviam como excluídos e, muitas vezes, sobreviviam com arrecadação de esmolas.

1 HOMERO. Ilíada. São Paulo: Difel, 1961. vs-216-219. 
$\mathrm{Na}$ Judéia antiga, dos tempos de Jesus Cristo, o destino das pessoas que tinham qualquer deficiência era esmolar para conseguir sobreviver. Os cegos, os amputados, os paralíticos pelas mais variadas causas, acabavam expostos pelos caminhos, ruas, logradouros e praças públicas (SILVA, 2003a, p. 1).

O "imperfeito", portanto, era considerado profano, não fazia parte dos rituais sagrados. "Toda alteração na situação de um indivíduo implica ações e reações entre profano e o sagrado, ações e reações que devem ser regulamentadas e vigiadas, a fim de a sociedade geral não sofrer nenhum constrangimento ou dano" (VAN GENNEP, 2012, p.24).

Aos moldes da Grécia, seguia a cultura ocidental, algumas superstições justificavam as deficiências como algo sobrenatural, outros casos se detinham na reclusão e torturas, como se vê na história do Corcunda de Notre-Dame, (PASCAL, 2007). Quasimodo foi abandonado aos quatro anos de idade pelos pais, à porta da Catedral devido à sua deformidade. Foi adotado por um pároco, que lhe deu a missão de guardar os sinos de Notre-Dame e após anos em contato com seu badalar, desenvolve surdez.

A partir do século XII, a filosofia aristotélica ditada ainda nos anos 300 a.C. domina verdadeiramente o pensamento europeu com o surgimento de novos filósofos. Entre eles, Agostinho e Tomás de Aquino, que desenvolveram uma abordagem original à filosofia e teologia, acomodando uma variedade de métodos e perspectivas. O sagrado se sobressai ao profano. A noção de kalokagathía também sofre influências, mudando para o que se pode chamar de "beleza interior", a beleza da alma e suas virtudes.

$\mathrm{Na}$ Renascença, as pessoas com deficiência serviram de tema de obras de artes. Rafaello (1483-1520), por exemplo, desenhou uma interessante gravura que se encontra no Museu de South Kensington (Londres). Ela nos mostra um homem paralítico na porta de um templo, aguardando ansiosamente os apóstolos Pedro e João (SILVA, 2003b). Podese encontrar quadros relevantes, tais como "Parábola dos Cegos", retratando uma cena em que vários cegos vão caindo em uma valeta, de autoria de Pieter Bruegel (1530 - 1569). Na literatura, o próprio Shakespeare no decorrer da peça tragédia Rei Ricardo III, por exemplo, identifica-o como "montão de ódio", "sapo", "massa ignóbil e disforme" (KAIL, 2005).

A kalokagathía passa, então, a ser mais um "reino próprio", um prazer desinteressado, incluindo moral e perfeição social; não só "uma mente sã e corpo são", mas também uma moral e dimensão social. Porém, ainda era longe o pensar que um ser dotado de anomalias pudesse se tornar um atleta.

\subsection{Ao mais-que-perfeito}

No mundo contemporâneo, o corpo passou a ser visto como um artefato de presença, que ostenta a identidade dos sujeitos. Para Mauss (2003) o corpo é o primeiro e o mais natural instrumento do homem. Vê-se então que "[...] o corpo e o conjunto das representações e práticas sobre ele, tornou-se objeto de reflexão, de conhecimento e de intervenção" (SOARES, 1997, p.106). Por sua vez, Sant'Anna (2001) entende que a aparência corporal, além de ser uma presença inscrita no corpo biológico, carrega consigo significados que são culturalmente construídos. Nesse sentido, algumas marcas corporais são significadas como sinais de beleza, de saúde e de perfeição, enquanto outras carregam consigo o estigma de serem vistas como sinal de feiura, de doença ou de deficiência, (SFEZ, 1996). Embora o foco deste trabalho não 
seja a discussão sobre a beleza, é necessário destacar que, do ponto de vista estético, o belo é relativo. Kant (1990, p.32) define o belo como algo que encanta, trazendo ao semblante do ser humano a viva sensação declarada por um olhar de "esplendorosa serenidade, por arroubos do sorriso e, muitas vezes, por um claro regozijo". Simmel (1988) trata a beleza como uma qualidade do ser humano, uma relação entre as partes e a imagem.

A partir dessa referência a história apresenta o belo do Movimento Paralímpico e de seus protagonistas. Os períodos de guerras trouxeram muitas consequências, entre elas sobreviventes com sequelas e mutilações. É nesse cenário que, em 1944, o neurocirurgião alemão Ludwig Guttman deixa seu país para trabalhar na Inglaterra no atendimento aos soldados sobreviventes. Entre suas observações, percebeu que muitos estavam morrendo por fortes infecções e feridas causadas pela falta de circulação sanguínea do paciente acamado e imóvel. Santos (1989) aponta que $80 \%$ desses pacientes iam a óbito na primeira semana por complicações ligadas a infecções urinárias, escaras de decúbito e infecções respiratórias. O neurocirurgião passou então a desenvolver técnicas para movimentá-los como parte da reabilitação desses indivíduos. Até ter a ideia de introduzir práticas esportivas dentro do hospital na tentativa de amenizar a dor, aliviar as feridas e a desesperança daqueles que tinham postulado o fim de suas vidas útil.

O objetivo da reabilitação dos soldados feridos em decorrência da guerra, naquele momento era prioridade dos governos dos países envolvidos nos conflitos e também da classe científica, pois a expectativa e a qualidade de vida chamavam a atenção para a necessidade de estudos (ARAÚJO, 1998, p. 20).

O período de guerra tinha pausado também a continuidade dos Jogos Olímpicos por 12 anos. Sua última edição havia acontecido em 1936 em Berlim. O retorno das edições aconteceu então em 1948, em Londres. Na ocasião, Dr. Guttman organizou uma disputa interna com seus 14 pacientes de cadeira de rodas, em alusão aos XIV Jogos Olímpicos, sediados na capital. Intitulou o evento de Stoke Mandeville Games e repetiu o feito anualmente, ampliando o número de atletas-pacientes, inclusive com intercâmbio de outros hospitais da região e até de outros países.

O esporte adaptado àqueles soldados de guerra passou a ser uma grande oportunidade de inclusão, conquistas, amizades, entre outros atributos que o esporte apresenta em sua faceta de megaevento como são os Jogos Paralímpicos. "[...] the event was an experiment as a public performance, but also a demonstration to society that sport was not just the domain of non-disable people" (GUTTMANN, 1952² apud BRITTAIN, 2010 p. 9).

Nos Jogos Olímpicos de Roma, 1960, o Stoke Mandeville Games deixa a Inglaterra e acontece também na capital italiana, oficializado como evento paralelo aos Jogos Olímpicos: "The vast majority of competitors and escorts have fully understood the meaning of the Rome Games as a new pattern of reintegration of the paralyzed into society, as well as the world of sport" (GUTTMAN, 1960 apud COMMITTEE, online) ${ }^{3}$.

Porém, Bailey (2008) afirma que somente em Tóquio, 1964, em seu discurso na cerimônia de abertura, Guttman chamou o evento oficialmente de Paralympic Games. "Depois disso houve outras tentativas de nomes como World Wheelchair Games, World Winter Games,

2 GUTTMANN, L. On the Way to an International Sports Movement for the Paralysed. The Cord, v. 5, n.3, p. 7 - 23, 1952. 
International Games for the Disabled, Olympiad for the Physically Disabled, Torontolympiad, Olympics for the Disabled e finalmente Paralympic Games". (BAILEY, 2008, p.8. Tradução nossa).

Em cada edição dos Jogos Paralímpicos, aumentava o número de atletas e países participantes. "O crescente interesse no esporte paralímpico tem acompanhado as performances cada vez melhores de para-atletas. Muitos são agora atletas em tempo integral e têm se beneficiado de programas de treinamento de alto rendimento tal como seus colegas Olímpicos" (CRAVEN, 2016, p.3 ). O bom e o belo passam representar muito além da aparência estética, aparecem na conquista da excelência. Na última edição, no Rio - 2016, os Jogos reuniram 4.500 atletas de 176 países. O Movimento Paralímpico alcança então, em sua plenitude, a kalokagathía intimamente relacionada com o conceito de aretē (virtude ou excelência), resgatado pelo Barão Pierre de Coubertin, ainda na criação dos Jogos Olímpicos da Modernidade em 1896.

Numa sociedade ética, homens e mulheres com deficiência física, congênita ou adquirida, devem ter acesso aos meios necessários para se tornarem cidadãos plenos. Se essa máxima funcionar, eles poderão escolher um dos diversos caminhos das habilidades e dos saberes para se sentirem realizados e serem reconhecidos como protagonistas destacados da história dessa mesma sociedade. Em todos esses campos, porém, emergem os fora de série, os que brilham intensamente (FURTADO; DUTTI, 2012, p.5).

O Brasil entrou no contexto dos Jogos em 1972 e alcançou sua melhor posição em Londres, 2012, ficando em sétimo lugar do mundo no quadro de medalhas, com 21 medalhas de ouro, 14 de prata e oito de bronze, somando 11 recordes mundiais e quatro recordes paralímpicos. Em 2016, o país caiu para oitavo lugar, muito embora tenha obtido mais medalhas do que em Londres. Ao todo foram 72, sendo 14 de ouro, 29 de prata e 29 de bronze, como mostra o quadro publicado pelo Comitê Paralímpico Internacional:

Figura 1 - Medalhas conquistadas pelo Brasil por ano de participação

\begin{tabular}{|c|c|c|c|c|c|c|c|c|}
\hline \multicolumn{9}{|c|}{ Medals By Year } \\
\hline \multicolumn{5}{|c|}{ Games } & Gold & Silver & Bronze & Total \\
\hline \multicolumn{5}{|c|}{1976 Toronto (Summer Games) } & 0 & 1 & 0 & 1 \\
\hline \multicolumn{5}{|c|}{1984 Stoke Mandeville (GBR), New York (USA) (Summer Games) } & 7 & 17 & 4 & 28 \\
\hline \multicolumn{5}{|c|}{1988 Seoul (Summer Games) } & 4 & 9 & 14 & 27 \\
\hline \multicolumn{5}{|c|}{1992 Barcelona (Summer Games) } & 3 & 0 & 4 & 7 \\
\hline \multicolumn{5}{|c|}{1996 Atlanta (Summer Games) } & 2 & 6 & 13 & 21 \\
\hline \multicolumn{5}{|c|}{2000 Sydney (Summer Games) } & 6 & 10 & 6 & 22 \\
\hline \multicolumn{5}{|c|}{2004 Athens (Summer Games) } & 14 & 12 & 7 & 33 \\
\hline \multicolumn{5}{|c|}{2008 Beijing (Summer Games) } & 16 & 14 & 17 & 47 \\
\hline \multicolumn{5}{|c|}{2012 London (Summer Games) } & 21 & 14 & 8 & 43 \\
\hline \multicolumn{5}{|c|}{2016 Rio de Janeiro (Summer Games) } & 14 & 29 & 29 & 72 \\
\hline \multicolumn{5}{|c|}{ Total medals (Summer \& Winter Games) } & 87 & 112 & 102 & 301 \\
\hline \multicolumn{9}{|c|}{ Recent Medals - Summer Games } \\
\hline \multicolumn{9}{|l|}{30} \\
\hline \multicolumn{9}{|l|}{24} \\
\hline \multicolumn{9}{|l|}{18} \\
\hline \multicolumn{9}{|l|}{12} \\
\hline \multicolumn{9}{|l|}{6} \\
\hline \multicolumn{9}{|c|}{2012} \\
\hline
\end{tabular}

Fonte: $<$ https://www. paralympic.org/sdms/hira/web/country/brazil>>4 


\subsection{Os rituais de passagem dos pré-olímpicos a paralímpicos}

Segundo a perspectiva de Van Gennep (2012), há incompatibilidade entre o mundo profano e o mundo sagrado, a tal ponto que a passagem de um ao outro não pode ser feita sem um estágio intermediário. O sociólogo francês vê a sociedade em geral como uma espécie de casa dividida em quatro corredores, com paredes tanto menos espessas e portas de comunicação tanto mais largas e menos fechadas. Para os diferentes e os semicivilizados estes compartimentos são isolados uns dos outros; e para passar de um ao outro são necessárias formalidades e cerimônias, com maior analogia de aceitação.

Todo indivíduo ou grupo que por seu nascimento ou por qualidades especiais adquiridas não têm direito imediato de entrar numa casa determinada desta espécie e instalar-se em uma destas subdivisões. Encontram-se assim em um estado de isolamento, que toma duas formas separadamente: São fracos por estarem fora desta sociedade especial ou geral, são fortes por estarem no mundo sagrado uma vez que esta sociedade constitui para seus membros o mundo profano (VAN GENNEP, 2012, p.41).

Essa analogia será aqui empregada para avaliar a passagem de atletas que estavam em plena trajetória de carreira olímpica e que por um acidente ou doença tiveram que reinventar suas carreiras no Movimento Paralímpico, que também é marcado por formalidades. Os ritos vivenciados não são diferenciados por eles em relação à rotina de treinos, jogos, competições, conquistas de índices, doping, recordes e pódios. Mesmo porque, segundo Huizinga (2000), 0 jogo, como elemento cultural, ultrapassa os limites da atividade puramente física ou biológica. O diferencial se estabelece, portanto, porque tal passagem exige um processo de classificação funcional para que 0 atleta prove sua deficiência, chamado elegibilidade (EXPLANATORY GUIDE, 2015, online). Ser elegível, segundo o Guia, é estar em condição de igualdade com os demais atletas de uma determinada prova, para que sua performance seja destacada. Tonon (2017) afirma que a classificação não é só uma prova de aptidões do atleta, em que ele comprova que sua deficiência é relevante no desempenho esportivo, mas um ponto norteador da sua carreira como atleta profissional.

Considerada a decomposição dos ritos de passagem, que Van Gennep (2012) faz entre "ritos de separação", "ritos de margem" e "ritos de agregação", a elegibilidade estaria presente nos três, porém, maior ênfase pode ser atribuída aos ritos de margem, na liminaridade, num período intermediário entre o sair da condição de pessoa com limitação física até ser efetivamente um atleta paralímpico. Os ritos de margem "[...] têm uma duração e complexidade que chega às vezes a lhes dar uma certa autonomia" (VAN GENNEP, 2012 p.128). Tal complexidade é possível ser observada no discurso abaixo:

Aí o processo de classificação no paraolímpico é bem complicado. Tem que chegar todo documentado lá, ter laudo médico. Fiz muitos exames e fui pra primeira classificação daí, na primeira eu já fiquei como Review, porque a minha baixa visão é muito incompatível com o que eu enxergo.

O velocista paralímpico Gustavo Henrique desenvolveu atrofia no nervo óptico já na sua juventude e perdeu parcialmente a visão. Antes deste diagnóstico, foi campeão brasileiro escolar, medalhista do campeonato sub-23 e medalhista na prova de revezamento $4 \times 100 \mathrm{~m}$ no Troféu Brasil. Em 2014 percebeu que estava queimando a corrida, pisando nas raias da pista, e num exame de rotina, foi alertado por um oftalmologista que estava fadado a perder 
a visão aos poucos. Seu processo de aceitação, a passagem de uma condição à outra, ainda não está concluído, como mostra em seu discurso: "Sei que é um processo. Não sei se esse processo pode demorar dez, 20 anos até entrar no ritmo, mas, aos poucos eu vou entendendo. É diferente eu carregar o termo de deficiente. É uma palavra que tem um peso muito grande".

Embora num processo de aceitação ainda não concluído, Gustavo mostra a kalokagathía como atleta paralímpico, ao conquistar a medalha de prata nos 200 metros rasos em Doha no Qatar em 2015. "Chegou na final eu falei assim, nem que eu chegue caindo eu vou terminar e eu vou dar o meu melhor aqui". Porém o ápice de seus resultados foi ganhar a medalha de ouro no revezamento 4x100 metros no Rio - 2016, vencendo a China e Uzbequistão, respectivamente. O tempo de 42"37 também deu ao quarteto o recorde paralímpico da prova. Nesse momento, 0 atleta usou as redes sociais para dividir com os torcedores a sua felicidade pela conquista: "Não sei o que escrever, só sei que estou muito feliz. Obrigado a todos brasileiros." (NASCIMENTO, 2016, online).

Ao exemplo dos ritos de separação, que "[...] compreendem, em geral, todos aqueles nos quais se corta alguma coisa, principalmente o primeiro corte de cabelos, 0 ato de raspar a cabeça, se vestir pela primeira vez" (VAN GENNEP, 2012, p. 51), encontra-se a história de vida do cavaleiro Rodolpho Riskala, que até 2015 estava em plena busca de índice olímpico para os Jogos Rio - 2016 quando foi acometido de uma meningite bacteriana cujas sequelas resultaram na amputação das duas mãos e os dois pés, necrosados pela alta febre que enfrentou. [...] Sei que quando eu acordei... é lógico que você tem aquele impacto, aquele choque. Eles tinham colocado uma coberta por cima, mas, logo eu quis ver e foi quase um alívio saber que tinham feito a amputação.

O atleta não teve tempo para se sentir um "anti-herói" ou lamentar sua deformidade. A continuidade de suas atividades com o cavalo e a vontade de competir, independentemente de suas condições físicas, destacam a kalokagathía, aqui tratada. Três meses depois de sua alta hospitalar, ainda sem ter muita adaptação com as próteses de perna, Rodolpho entrou na Arena Paralímpica em Deodoro, Rio-2016 e conseguiu o 10 lugar do mundo em adestramento, embalado pela música "Mais que nada sai da minha frente que eu quero passar", de Jorge Ben Jor : "Olha, eu sempre fui do cavalo. [...] Montar foi uma das coisas que realmente me motivou um monte pra poder passar essa fase de hospital, readaptação, aceitação comigo mesmo, tudo isso eu acho que isso aqui foi bárbaro, não tinha o que falar".

Já os ritos de agregação, que têm por finalidade, segundo Van Gennep (2012), introduzir a criança ao mundo, ou ainda, ser a passagem para uma nova situação (batismo, casamento, entre outros), ainda não vivida pelo indivíduo, são evidenciados na história da ex-triatleta Susana Schnarndorf, que soma 13 Ironman em sua carreira, representou a seleção brasileira nos Jogos Pan-americanos de Mar Del Plata, 1995. Sua agregação ao mundo paralímpico veio após receber o diagnóstico de Atrofia Múltipla do Sistema (SMA), doença degenerativa que a tirou do cenário olímpico do triatlo. Aconselhada a não parar com o esporte, ia rotineiramente nadar para prolongar seus dias com mais qualidade: "[...] eu passei todas as fases, primeiro raiva, depois pena de mim mesmo, depois depressão, foi o ciclo todo. Todos que têm trauma passam por isso. Já conversei com tantas pessoas e você pergunta, por que comigo?"

Durante a sua busca por novos diagnósticos e reversão do quadro, foi vista pelo técnico da seleção brasileira de natação paralímpica, que a convidou para nadar na equipe. De início teve preconceito consigo mesma pela idade e condição psicológica em que se encontrava, mas 
seu ritual de passagem para o esporte paralímpico significou também aceitação da sua nova condição física. Foi classificada como classe S8 (S de Swimm 8 - pouco comprometimento físico, numa escala de 10 a 1) e em suas primeiras já bateu cinco recordes brasileiros. Porém, a doença progrediu e consequentemente foi submetida a novas reclassificações: "Minha primeira competição no paraolímpico foi o marco da minha vida. Quando empurrei o bloco de largada, empurrei junto tudo de ruim que estava passando e, ao mergulhar, mergulhei numa fase que nunca imaginei que ia acontecer, nunca imaginei o que me esperava."

O bom e o belo de Susana vêm, então, em dois momentos: primeiro quando ela se consagra campeã mundial do nado peito em 2013, na classe SB6: "Eu olhei o placar e não consegui enxergar o resultado. Aí virei para a arquibancada e vi um monte de gente apontado o dedo indicador simbolizando o número um e gritando: - campeã mundial, campeã mundial". A vitória the coroou como a melhor atleta paralímpica brasileira de 2013. Seu segundo momento de excelência foi ter conquistado a medalha de prata no revezamento $4 \times 50$ metros no Rio - 2016. O fato motivou a atleta a continuar sua luta pela vida na água. Ao conceder uma entrevista nos Jogos, um repórter japonês arriscou perguntar em português: - 'Susana, vai conseguir nadar até 2020?" E ela respondeu: "- Susana Tóquio, 2020! Não vou parar não. Vou até lá".

As passagens de uma condição física a outra, mencionadas pelos atletas, do corpo que era perfeito para o fisicamente comprometido, são pontuadas neste artigo representando a importância de tal momento sofrido por eles. Mas o alcance da excelência de seus feitos após a deficiência reforça o título "mais-que-perfeito" atribuído a eles neste texto, relativizando as mais diversas opiniões. "Os atletas paralímpicos são capazes de feitos extraordinários e a deficiência deles é apenas uma característica entre as várias que definem um ser humano. Nem a mais importante nem a menos importante. São atletas de alto rendimento e a grande maioria daqueles que disputam os Jogos Paralímpicos vive do esporte e para o esporte" (PARSONS, 2016, p.2).

\section{CONSIDERAÇÕES FINAIS}

Pessoas que se esforçam para exemplificar um conjunto ideal de valores pessoais, sociais e estéticos, independentemente de sua condição física, transcendem o comum, saem da média. As características da kalokagathía, o "bom e o belo", foram ressaltadas nos discursos dos atletas colaboradores através da continuidade de suas carreiras como atletas. Foi percebido neles o amor à vida acima das condições de vida. Nesse sentindo destaca-se a frase de Mazon: "O amor à vida torna-se, por isso mesmo, o princípio e a razão do heroísmo: aprende-se a colocar a vida num plano muito alto para sacrificá-la à glória, que há de perpetuála [...]" (BRANDÃO, 1986, p.23).

A condição do ser humano, seja corporal, pois é seu corpo que o separa do outro, que o individualiza, que estabelece a fronteira da sua identidade pessoal. A passagem para o esporte paralímpico gerou, aos atletas estudados, nova identificação com aqueles que se encontram na mesma situação. $O$ que se vê e se ouve desses atletas é o amor à vida reluzindo acima de qualquer musculatura atrofiada, de qualquer penumbra no campo visual ou de qualquer parte faltante do corpo. Faltar uma parte desse corpo não o faz menos herói. A essência desse título já vem com ele: "De qualquer forma, exatamente por ser um herói, a criança já vem ao mundo 
com duas 'virtudes' inerentes à sua condição e natureza: a timÇ (timé), a 'honorabilidade pessoal' e a £retÇ (areté), a 'excelência', a superioridade em relação aos outros mortais" (BRANDÃO, 1987, p.23). E tais características não dependem do corpo físico.

\section{REFERÊNCIAS}

AMARAL, Lígia Assunção. Pensar a diferença/deficiência. Brasília: Corde, 1994.

ARAÚJO, Paulo Ferreira de. Desporto Adaptado no Brasil: Origem, Institucionalização e Atualidade. Indesp, Brasília, 1998.

BACHELARD, Gaston. A intuição do instante. 1. ed. Campinas, SP: Verus, 2002.

BACHELARD, Gaston. A intuição do instante. 2. ed. Campinas, SP: Versus, 2010.

BACHELARD, Gaston. L'Intuition de l'Instant. 11. ed. Paris: Librairie Générale Française, 2016.

Dépot légal 1. ed. 1994.

BAILEY, Steve. Athlete First: a history of the Paralympic Movement. Winchester: John Wiley \& Sons, 2008.

BENJAMIN, Walter. Obras escolhidas: magia e técnica, arte e política. São Paulo: Brasiliense, 1987.

BRANDÃO, Junito de Souza. Mitologia Grega. Petrópolis: Vozes, 1986. v 1.

BRANDÃO, Junito de Souza. Mitologia Grega. Petrópolis: Vozes, 1987. v. 3.

BRITTAIN, lan. The Paralympic Games Explained. London: Routledge, 2010.

COMMITTEE International Paralympic (Org.). Roma 1960: Closing Ceremony. 2018. Disponível em: <https://www.paralympic.org/rome-1960>. Acesso em: 04 out. 2018.

CRAVEN, Philip. [Apresentação]. In: PAPPOUS, Athanasios (Sakis); SOUZA, Doralice Lange de. Guia para a mídia: como cobrir os Jogos Paralímpicos Rio 2016. Disponível em: <https://cev.org.br/ arquivo/biblioteca/4032325.pdf>. Acesso em: 04 out. 2018.

DaMATTA, Roberto. Apresentação. In: VAN GENNEP, Arnold. Os Ritos de Passagem. Petrópolis: Vozes, 2012. p. 9-20.

DÜRRIGL, Marija-Ana. Kalokagathia: Beauty is more than just external appearance. Journal of Cosmetic Dermatology, v.1, p. 208-210, 2002.

EXPLANATORY guide to Paralympic classification Paralympic summer sports. Bonn: International Paralympic Committee Bonn, sept.2015. Disponível em: < https://m.paralympic.org/sites/default/files/ document/150915170806821_2015 09 15+Explanatory+guide+Classification_summer+FINAL+_1.pdf >. Acesso em: 11 dez. 2017.

FARIAS, Luis Antônio. Opiniões Voláteis: opinião pública e geração de sentido. 2018. 121 f. Tese (Livre Docência) - Escola de Comunicação e Artes. Universidade de São Paulo, São Paulo, 2018. 
FURTADO, Bernardino; DUTTI, Sérgio. Vencedores. Brasília: Abecer, 2012.

GOMES, Maria Helena Scalabrin Cardoso. Inclusão da Pessoa com Deficiência no Mercado de Trabalho: gestão, direitos e efetividade. 2014. 272 f. Tese (Doutorado) - Curso de Administração, Universidade Municipal de São Caetano do Sul. São Caetano do Sul, 2014. Disponível em: <http:// repositorio.uscs.edu.br/bitstream/123456789/551/2/TESE PPGA MARIA\%20HELENA\%20S\%20 CARDOSO.pdf>. Acesso em: 23 fev. 2018.

GUTTMANN, Ludwig. Sport for the Physically Handicapped. Paris: Unesco, 1976.

HARDIN Marie; HARDIN Brent. "The 'Supercrip' in Sport Media: Wheelchair Athletes Discuss Hegemony's Disabled Hero". Sociology of Sport Online, v. 7, n. 1, p. 1-14, 2004.

HUIZINGA, Johan. Homo Ludens: O jogo como elemento da cultura. São Paulo: Perspectiva, 2000.

INTERNATIONAL PARALYMPIC COMMITTEE. IPC Sport Data Management System. Bonn, 2018. Disponível em: <https://db.ipc-services.org/sdms/app/login>. Acesso em: 04 out. 2018.

KAIL Aubrey C. The Medical Mind of Shakespeare. The Ambassadors online magazine, v.8, n.1, jan.2005. Disponível em: <http://ambassadors.net/review.htm>. Acesso em: 20 jan. 2018.

KANT, Immanuel. Observaciones acerca del sentimiento de lo bello e de lo sublime. Tradução de Luís Jiménez Moreno. Madrid: Alianza, 1990.

LEVÍTICO. In: Bíblia online. Disponível em: <https://www.bibliaonline.com.br/acf//v/21>. Acesso em: 22 jan. 2018.

LIDDEL, Henry George; SCOTT, Robert A. Greek-English Dictionary. Oxford: Clarendon, 1968.

MARCOS. In: Bíblia online. Disponível em: < https://www.bibliaonline.com.br/act/mc/2>. Acesso em: 22 jan. 2018.

MAUSS. Marcel, Sociologia e Antropologia. São Paulo: Cosac Naify, 2003.

NASCIMENTO, Ronaldo. Velocista Gustavo Henrique festeja conquista do ouro em rede social. Globo Esporte, Rio de Janeiro, 13 set. 2016. Disponível em: <http://globoesporte.globo.com/sp/presidenteprudente-regiao/paralimpiadas/noticia/2016/09/velocista-gustavo-henrique-festeja-conquista-do-ouroem-rede-social.html>. Acesso em: 23 fev. 2018.

PARSONS, Andrew. [Apresentação]. In: PAPPOUS, Athanasios Sakis; SOUZA, Doralice Lange de. Guia para a mídia: Como cobrir os Jogos Paralímpicos Rio 2016. Disponível em: <https://cev.org.br/ arquivo/biblioteca/4032325.pdf>. Acesso em: 04 out. 2018.

PASCAL Tonazzi. Florilège de Notre-Dame de Paris (anthologie). Paris: Arléa, 2007.

RUBIO, Katia. 0 atleta e o Mito do Herói: o imaginário esportivo contemporâneo. São Paulo: Casa do Psicólogo, 2001.

RUBIO, Katia. Narrativas Biográficas: a construção de um método. São Paulo: Laços, 2016.

SANT'ANNA, Denise Bernuzzi. Corpos de passagem: ensaios sobre a subjetividade contemporânea. São Paulo: Estação Liberdade, 2001.

SFEZ, Lucien. A saúde perfeita: crítica de uma nova utopia. São Paulo: Loyola, 1996. 
SILVA, Oto Marques da. Epopéia Ignorada: a história da pessoa deficiente no mundo de ontem e de hoje. São Paulo: Cedas, 1987.

SILVA, Oto Marques da. Jesus Cristo e as pessoas com deficiência. 2003a. Disponível em: <http:// www.crfaster.com.br/JC.htm>. Acesso em: 19 jan. 2018.

SILVA, Oto Marques da. Pessoas com deficiência em quadros dos grandes mestres. 2003b.

Disponível em: <http://www.crfaster.com.br/Pintura.htm>. Acesso em: 19 jan. 2018.

SIMMEL, Georg. Filosofia do amor. São Paulo: Martins Fontes, 1988.

SOARES, Antônio Jorge Gonçalves. Velhos esportistas: utilidade e estética. Motus Corporis, v.4, n.2, p.102-120, 1997.

TONON, Luciane Maria Micheletti. A influência da elegibilidade na carreira do atleta paraolímpico. Olimpianos: Journal of Olympic Studies, v. 1, n. 1, p. 79-89, maio 2017. Disponível em: <http:// olimpianos.com.br/journal/index.php/Olimpianos/article/view/6/7>. Acesso em: 23 fev. 2018.

VAN GENNEP, Arnold. Os Ritos de Passagem. Petrópolis: Vozes, 2012. 
